\title{
Incursóes no percurso profissional: análise crítica de minha trajetória
}

\author{
Marcella Guimaráes Assis \\ Professora Titular, Diretora de Políticas de Extensão, Departamento de Terapia Ocupacional e \\ Programa de Pós-graduação em Ciências da Reabilitação, Universidade Federal de Minas Gerais - UFMG, \\ Belo Horizonte, MG, Brasil

\begin{abstract}
Resumo: Este ensaio apresenta minha trajetória profissional, descrita no memorial elaborado para o concurso de professor titular na Universidade Federal de Minas Gerais, em 2012. Tendo a gerontologia como área de atuação profissional, iniciei minha trajetória pelo ensino, extensão e administração e posteriormente enveredei pelos caminhos da pós-graduação e da pesquisa. A temática sobre a funcionalidade do idoso tem sido a tônica das minhas investigações. Minha trajetória como professora, orientadora e pesquisadora é marcada pelo envolvimento e pela obstinação na busca de conhecimento e de aprimoramento. Percorro uma trajetória dinâmica que engloba frentes diversificadas de atuação, na qual procuro desenvolver parcerias profissionais e estreitar laços de amizade para tornar essa travessia mais leve e compartilhada. Sigo aprendendo, pesquisando, produzindo, publicando, ensinando!
\end{abstract}

Palavras-chave: Pesquisa, Terapia Ocupacional, Gerontologia.

\section{Professional career incursions: a critical analysis of my trajectory}

\begin{abstract}
This essay outlines my professional trajectory described in the Memorial prepared for the full professor application process at the Federal University of Minas Gerais in 2012. Gerontology is the field of my professional practice; I began my career teaching, coordinating community services and assuming administrative positions, and later on undertook graduate studies and research. Issues related to the functionality of the elderly have been the focal point of my investigation. My career trajectory as a professor, advisor and researcher has been marked by commitment and obstinacy in the search for knowledge acquisition and enhancement. I follow a dynamic path that encompasses diverse areas of activity in which I place effort on developing professional partnerships and tightening established friendships to make this endeavor lighter and more shared with others. I continue my trajectory learning, researching, producing, publishing, and teaching.
\end{abstract}

Keywords: Research, Occupational Therapy, Gerontology.

Autor para correspondência: Marcella Guimarães Assis, Escola de Educação Física, Fisioterapia e Terapia Ocupacional, Universidade Federal de Minas Gerais, Av. Presidente Antônio Carlos, 6627, Campus Pampulha, CEP 31270-901, Belo Horizonte, MG, Brasil, e-mail: mga@ufmg.br

Recebido em 3/6/2013; Aceito em 15/7/2013. 


\section{Apresentação}

Dando prosseguimento à publicação da trajetória dos pesquisadores, pelos Cadernos de Terapia Ocupacional da UFSCar, apresento parte de meu memorial elaborado para o concurso de professor titular da Universidade Federal de Minas Gerais, em 2012.

Nesse memorial apresento minha trajetória profissional e, por acreditar que ela esteja intricada com minha história pessoal, inicio discorrendo sobre essa história.

\section{Minha história}

A escolha pela Terapia Ocupacional resultou do meu interesse pelo cuidado, pelo cuidar do outro. $\mathrm{Na}$ juventude promovia visitas a uma instituição para idosos. Hoje penso que meu interesse em trabalhar na área de gerontologia se consolidou a partir da convivência com meus avós e dessa experiência das visitas à instituição para idosos.

Diversos familiares, amigos e colegas marcaram minha trajetória em distintos cenários e fases da vida. Essas pessoas contribuíram para a minha formação pessoal e deixaram suas marcas também na minha formação profissional. O passar do tempo esmaece algumas lembranças mas aviva outras. Ao relembrar as pessoas que fazem parte da minha história, ao tornar presentes os que se ausentaram, numa tentativa de mesclar de forma equilibrada memória e análise, refaço a trajetória percorrida e vislumbro novos caminhos.

\section{A formação em Terapia Ocupacional}

Iniciei meu curso de graduação em Terapia Ocupacional em 1980, na Faculdade de Ciências Médicas de Minas Gerais. O curso era constituído por disciplinas eminentemente do currículo médico e por apenas três disciplinas específicas. Éramos dez colegas com pouca informação e conhecimento sobre a Terapia Ocupacional. Frente a esse panorama pouco elucidativo sobre a profissão, iniciei a busca por conhecimentos pelos estágios extracurriculares.

Estagiei nas áreas de saúde mental, neurologia infantil e gerontologia. Nesses estágios aprendi sobre a atuação clínica do terapeuta ocupacional, entrei em contato com equipes de profissionais e com o desafio de trabalhar em conjunto. O exercício do trabalho em equipe, tão propagado e táo difícil, requer profundo saber sobre o próprio fazer e humildade para ouvir e compreender o outro no que não se sabe.

Desenvolvi também um trabalho voluntário com estudantes de Medicina e de Fisioterapia da faculdade em uma instituiçáo para idosos de Belo Horizonte. O grupo de voluntários fazia visitas semanais e cada profissional desenvolvia um projeto relacionado à sua área. Para desenvolver nossas atividades, referenciávamo-nos no único livro da profissão disponível, dos autores Willard e Spackman, em sua primeira edição espanhola (WILLARD; SPACKMAN, 1973). Essa experiência possibilitou a confirmação de meu interesse pela área do envelhecimento e inaugurou a travessia pelo voluntariado, que continuaria mais tarde com outros grupos.

$\mathrm{Na}$ faculdade participei de eventos científicos e apresentei meu primeiro trabalho. Frente à reduzida produção científica na Terapia Ocupacional, escrever um trabalho foi um grande desafio. Se, por um lado, quem apresenta um trabalho se expóe à crítica, nem sempre construtiva, por outro lado essa experiência gerou um momento profícuo de reflexão e avanço na construção do conhecimento. E desse evento resultou uma vontade ainda mais acirrada de seguir produzindo, comunicando o aprendido e aprendendo mais.

Buscando aprofundar a compreensão da atuação profissional, passei a fazer cursos de curta duração. Participei do curso de extensáo Recursos terapêuticos em Terapia Ocupacional, promovido pela Universidade Federal de Minas Gerais. Entrei, assim, em contato com as atividades de extensão que posteriormente permeariam minha trajetória acadêmica.

No último ano da graduação fui aprovada na seleção para estagiária bolsista na Fundação Hospitalar do Estado de Minas Gerais (Fhemig) e fiz um ano de estágio com crianças em sofrimento mental. Esse foi um ano de intensa aprendizagem, com estágios curriculares pela manhã e extracurriculares à tarde.

Os quatro anos de faculdade foram marcados pela busca incessante por conhecimentos e experiência profissional, numa época em que havia ínfima produção científica sobre Terapia Ocupacional e reduzido número de profissionais. Muitas perguntas ficaram sem resposta, inúmeras dúvidas e incertezas persistiram, mas a determinação de me tornar terapeuta ocupacional foi maior e me impulsionou a seguir, abrindo trilhas paralelas ao caminho existente. Uma vez concluído o curso de graduação, surgiu um novo desafio: a inserção no mercado de trabalho. 


\section{O exercício da Terapia Ocupacional e da docência}

Os quatro anos de faculdade possibilitaram a definição da área de atuação profissional: a gerontologia. Mas a entrada no mercado de trabalho, em 1984, apontou outra direção. Iniciei minha carreira profissional em duas atividades: na clínica em saúde mental, no Hospital Raul Soares, e na docência, inicialmente na Faculdade de Ciências Médicas de Minas Gerais (FCMMG) e, posteriormente, na Universidade Federal de Minas Gerais (UFMG). Meu desejo de atuar na área da gerontologia continuava presente e eu me dedicava, cada vez mais, à leitura e ao estudo do tema. Entretanto, a oportunidade surgida na área de saúde mental me fez enveredar por outro caminho e adiar, temporariamente, o desejo.

Também em 1984 comecei a participar da Associação dos Terapeutas Ocupacionais de Minas Gerais (ATOMG), como diretora cultural. Essa atuação na associação se estendeu por vários anos, em que assumi o cargo de conselheira fiscal e, posteriormente, de vice-presidente. Nos vários mandatos atuei com colegas com experiência profissional em diversas áreas e juntos realizamos eventos científicos e discussões sobre a atuação profissional. Entre os eventos destaco o V Congresso Brasileiro e IV Simpósio Latino Americano de Terapia Ocupacional (1997), em Belo Horizonte.

Esse congresso reuniu, durante quatro dias, cerca de 900 profissionais e acadêmicos e contou com ilustres presenças internacionais, como o prof. dr. Gary Wayne Kielhofner, teórico de destaque na profissão, e a terapeuta ocupacional Anne Spencer, representante da Federação Mundial de Terapia Ocupacional (WFOT). O dr. Kielhofner, que faleceu em setembro de 2010, foi um cientista aclamado internacionalmente cujo trabalho centrou-se no desenvolvimento do Modelo de Ocupação Humana. As discussóes foram empolgantes e produtivas e geraram trocas de conhecimento e aquisição de novas informaçóes referentes às intervençôes nas diversas faixas etárias e áreas profissionais.

Participar da ATOMG no início da minha carreira profissional possibilitou estabelecer valiosas parcerias de trabalho e receber o estímulo fundamental para persistir na busca de aprimoramento profissional e para descortinar as possibilidades de intervenção. A ATOMG possibilitou-me, ainda, ingressar na atividade de organização de eventos científicos, tarefa que demanda as habilidades de congregar pessoas, explorar o potencial de participaçáo de cada um, flexibilizar as decisóes e, também, ousar nas propostas e inovar nas soluçóes. A organização dos eventos foi sempre um processo de crescimento e aprendizagem profissional e pessoal e uma atividade que tem se repetido em minha vida acadêmica.

\subsection{A clínica no Hospital Raul Soares}

No Hospital Raul Soares, da Fhemig, atuei durante dois anos junto a indivíduos adultos em sofrimento mental na internaçáo e no ambulatório. Nesse hospital aprimorei as metodologias de atendimento, em grupo e individual, e aprofundei os conhecimentos sobre os quadros clínicos nas reuniōes de discussão de casos e de equipe multiprofissional.

Em 1985 integrei o grupo interdisciplinar, designado pela Secretaria Estadual de Saúde de Minas Gerais, que participou do Projeto de Reestruturação do Centro Hospitalar Psiquiátrico. Esse centro, localizado em Barbacena, era uma das unidades da Fhemig e, durante o mês de maio, a equipe profissional avaliou todos os pacientes adultos e adolescentes internados. Essa experiência marcou de modo impar a minha passagem pela saúde mental, uma vez que presenciei o cuidado precário destinado aos pacientes internados, o número insuficiente de profissionais, a ausência de apoio familiar e a superlotação institucional. Por outro lado, a convivência com os profissionais da equipe de avaliação, durante um mês, foi marcada pela aprendizagem produtiva e intensa, pela troca generosa e pelo diálogo eloquente, empolgado e franco.

O trabalho no Hospital Raul Soares, acrescido dessa experiência pontual, mas marcante, em Barbacena, gerou muitas questôes referentes às políticas públicas. Esse novo questionamento impulsionou-me para a entrada na pós-graduação. Em 1985, ingressei no curso de especialização em Saúde Pública na Escola de Saúde de Minas Gerais (Esmig). Na especialização com ênfase multiprofissional, convivi com colegas de diferentes áreas do conhecimento, mas todos marcados pelo espírito questionador e pelo envolvimento com as questóes sociais. Foi um período produtivo permeado por vastas descobertas e reflexóes. Meu trabalho de conclusão de curso teve por título Aspectos da morbidade em um hospital público na área de saúde mental.

A atuação clínica associada ao processo de aprendizagem na especialização resultou numa postura mais crítica frente à intervenção profissional e na ampliaçáo da percepçáo do sofrimento mental. Nessa primeira experiência profissional, sistematizei e ampliei o conhecimento e estabeleci relaçóes duradouras de companheirismo e amizade com diversos profissionais que até hoje estão presentes na minha trajetória. 


\subsection{A docência na Faculdade de Ciências Médicas de Minas Gerais}

A carreira docente chamou minha atençáo desde o período da graduação em Terapia Ocupacional. As diferentes metodologias utilizadas pelos professores, a forma de transmitir e de estimular o estudante, a condução da disciplina com suas exigências ora rígidas, ora flexíveis foram alguns dos aspectos que despertaram meu interesse pela função de ensinar e pelo papel de professor. Assim, paralelamente à atuação clínica, mantive o desejo de ingressar no universo acadêmico. No ano de 1985 fui indicada para ministrar a disciplina Terapia Ocupacional aplicada à Psiquiatria, na Faculdade de Ciências Médicas de Minas Gerais. Ser professora na faculdade em que me formei, indicada para a função por um ex-professor, foi motivo de orgulho e expectativa. $\mathrm{O}$ desafio era grande e me dediquei muito para exercer a função.

O trabalho no Hospital Raul Soares possibilitou melhor associação da teoria com a prática e a ampliação do escopo de ilustrações durante as aulas. Contribuiu também para o meu desempenho como professora o curso que frequentei no final de 1984: Metodologia do ensino superior aplicada à área de saúde. Esse curso foi promovido pelo Departamento de Terapia Ocupacional da Faculdade, com a colaboração do Programa de Apoio Pedagógico aos Profissionais da Saúde da Coordenação de Aperfeiçoamento de Pessoal de Nível Superior (Capes). O investimento e a dedicação resultaram no convite para assumir outra disciplina. E em 1987 ministrei também a disciplina Saúde Pública no Brasil para os cursos de Fisioterapia e de Terapia Ocupacional.

Meu empenho foi reconhecido pela homenagem - homenageada especial - da turma de dezembro de 1986 e pelo convite para ser paraninfa dos formandos de 1987. No final do ano de 1987 deixei a faculdade após aprovação em concurso público para professora na Universidade Federal de Minas Gerais. Assim se inaugurou mais um capítulo da minha história: a docência na UFMG.

\section{A docência na UFMG}

Minha trajetória no Departamento de Fisioterapia e Terapia Ocupacional da UFMG iniciou-se em 1986, quando ministrei, como professora substituta, a disciplina História da Terapia Ocupacional. Após essa experiência, fui aprovada em concurso público, em 1988, para o cargo de professora auxiliar, com regime de dedicaçáo exclusiva. Chegar a uma universidade pública do porte da UFMG foi um desafio que procurei enfrentar com empenho, dedicação e ousadia, mas também com humildade para aprender com a instituição e com minhas colegas, algumas das quais tinham sido minhas professoras na graduação. No início, as frentes de trabalho foram variadas, incluindo ministrar disciplinas, realizar projetos de ensino e de extensão, participar da administração nos órgãos colegiados. Com o passar do tempo, outras frentes foram se apresentando, como a necessidade de ingressar na pós-graduação e na pesquisa.

\subsection{As disciplinas}

No curso de graduação em Terapia Ocupacional ministrei diversas disciplinas. Apesar da diversidade de conteúdos abordados, relativos a diferentes faixas etárias, ao longo dos anos direcionei gradativamente minha atuação para as disciplinas relacionadas à intervenção do terapeuta ocupacional com a população idosa. O grande desafio foi e ainda hoje é motivar o estudante para direcionar o olhar para o idoso, para entender a velhice como uma fase da vida e para compreender as diferentes nuanças do processo de envelhecimento.

Esse desafio tornou-se ainda maior durante o processo de supervisão da prática clínica. $\mathrm{O}$ estágio realizado em instituiçóes de longa permanência para idosos póe o estudante frente às necessidades de avaliar e intervir junto a um indivíduo idoso. Ideias preconcebidas, mitos e medos se misturam durante essa experiência, que para muitos é uma prestação de cuidado inédita. Nesse contexto, as supervisōes são espaço para explorar o desconhecido, suscitar a curiosidade, aguçar os sentidos, tecer reflexóes e implementar a intervenção. Um desafio tanto para o professor quanto para o aluno, que devem, juntos, percorrer estradas e abrir trilhas.

Paralelamente às disciplinas obrigatórias, ministrei algumas optativas, como Promoção da Saúde do Idoso e Roda de Conversa: construindo um conhecimento sobre o envelhecimento ativo. Essas disciplinas tornaram-se momentos muito peculiares e especiais na transmissão do conhecimento, uma vez que os estudantes as elegem a partir de seu interesse e motivação e, assim, a participação e o envolvimento sáo diferenciados. Para os docentes, acredito que também ocorra algo similar. Pessoalmente, tenho grande interesse na oferta dessas disciplinas, em que posso inovar no conteúdo e ousar na introdução de discussóes inéditas. A disciplina Roda de Conversa tem sido uma experiência gratificante. As rodas de conversa propiciam interaçóes, circulação de conhecimentos em análise (CAMPOS, 2003) e 
motivam os estudantes a buscarem as informaçóes de modo mais ativo e reflexivo. Os estudantes a têm avaliado positivamente e as discussóes têm despertado mais interesse em relaçáo ao processo de envelhecimento.

Em 2010 foi implantado o novo currículo do curso de Terapia Ocupacional, após longo período de trabalho da Comissão de Elaboração da Nova Proposta Curricular, a qual integrei desde 2004. A proposta do novo currículo é inovadora e está em consonância com a atual perspectiva da Organização Mundial de Saúde (OMS) que, em 2001, aprovou um modelo de classificação revisado, denominado Classificação Internacional de Funcionalidade, Incapacidade e Saúde (CIF). A adoção desse modelo possibilitará inovação na formação profissional do terapeuta ocupacional na UFMG, pois implicará o deslocamento da formaçáo centrada na doença para a busca por qualidade de vida e independência dos sujeitos no seu cotidiano, no que se refere às atividades de vida diária, trabalho/atividades produtivas, lazer, brincadeiras, indo ao encontro das tendências teórico-práticas da formação do terapeuta ocupacional.

Nas discussóes iniciais da comissão de reforma curricular foi identificada a necessidade de inovar também nas metodologias de ensino. E quando, em 2005, surgiu a proposta de especialização em Ativação de Processos de Mudança na Formação Superior de Profissionais de Saúde, promovida pelo Ministério da Saúde/Fundaçáo Oswaldo Cruz (Fiocruz), vislumbrei a valiosa oportunidade de reciclar conhecimentos e aprender sobre novas metodologias. A especialização foi um espaço privilegiado para partilhar aprendizados com docentes de outras instituições de ensino superior, para incorporar inúmeras estratégias de mudança na formação e para aprender novas metodologias de ensino/aprendizagem. A partir dessa especialização introduzi nas disciplinas que ministro as metodologias ativas de ensino. Os resultados positivos puderam ser constatados desde o primeiro semestre de implantação, com os estudantes se mostrando mais envolvidos e ativos no processo de aprendizagem.

Ministrar disciplinas no curso de graduação da Terapia Ocupacional exige o olhar atento para desvelar a delicada relação professor-estudante. Essa relação extrapola as questōes pedagógicas e engloba também relaçóes intersubjetivas.

\subsection{Os projetos de ensino}

Os primeiros projetos de ensino que desenvolvi no departamento, em 1988, foram relacionados à biblioteca setorial e aos materiais e equipamentos utilizados nos laboratórios do Curso de Graduação em Terapia Ocupacional.

Nos anos 1990 participei, em parceria com professores de Terapia Ocupacional e de Fisioterapia, de vários outros projetos: Projeto de Implantação do Curso de Especialização em Ciência do Movimento (1991 a 1994), Adequação do Questionário de Avaliação dos Docentes pelos Discentes (1992 a 1994) e Normatização dos Trabalhos de Monografia de Conclusão do Curso de Terapia Ocupacional (1999). O trabalho em parceria com os colegas da Fisioterapia possibilitou a ampliaçáo do olhar para a complexa área da saúde e o posterior desenvolvimento de trabalhos em projetos interdisciplinares.

Dando continuidade ao estabelecimento de parcerias, no período de 2003 a 2006 participei do projeto de ensino Proposta de Integração dos Ciclos Básico, Pré-profissionalizante e Profissionalizante do Curso de Terapia Ocupacional (PID). Esse projeto objetivou contribuir para a articulação dos conteúdos ministrados nas disciplinas oferecidas pelo ciclo básico com os das disciplinas dos ciclos pré-profissionalizante e profissionalizante, reafirmando a importância do ciclo básico para a prática profissional. $\mathrm{O}$ projeto visou, ainda, acolher o estudante em seu ingresso no curso e na UFMG e propiciar aos acadêmicos bolsistas uma experiência na iniciação à docência.

Em 2006 e 2007 participei do projeto de ensino Apoio à Implantação do Projeto Pedagógico do Curso de Terapia Ocupacional (PAE), que objetivou preparar o corpo docente e discente do curso de Terapia Ocupacional para a implantação do novo projeto pedagógico e instrumentalizar os docentes para a utilização de metodologias ativas de ensino/ aprendizagem. Esse projeto contou com a participação de diversos docentes do departamento e de acadêmicos bolsistas. No PAE tive a oportunidade de ampliar a utilização do conhecimento sobre metodologias ativas adquiridos na especialização Ativação de Processos de Mudança na Formaçáo Superior de Profissionais de Saúde. O desenvolvimento desse projeto possibilitou aos bolsistas a experiência coletiva de análise e aplicação de novas metodologias de ensino/aprendizagem e despertou no corpo discente do curso o interesse por aprender no cotidiano profissional. Outro resultado foi a produção de material didático sobre as metodologias ativas, com a compilação dos textos pesquisados para o corpo docente. Essa experiência exitosa foi divulgada em evento científico da UFMG (TIRADO, 2006) e da área de Terapia Ocupacional (BRAGA et al., 2007).

De 2008 a 2010 participei do Programa Especial de Graduação (PEG): Mudança de Cenário na Aprendizagem da Promoção de Saúde. Esse programa 
objetivou inserir o estudante bolsista em um novo cenário de prática, nas Unidades Básicas de Saúde, e integrá-lo às equipes do Núcleo de Apoio à Saúde da Família - Reabilitaçáo (NASF-R), visando à construção de conhecimentos e ao desenvolvimento de açôes específicas da Terapia Ocupacional no âmbito da atenção básica em saúde.

A partir da análise crítica dessa vivência, o estudante deveria propor novas açóes articuladas à sua formação profissional, visando aprimorar o atendimento realizado e introduzir propostas factíveis para responder às demandas da comunidade. Essa dinâmica objetivou a construçáo do conhecimento no cotidiano das ações de saúde.

O PEG possibilitou ampliar os espaços de aprendizagem, desenvolver a habilidade de resoluçáo de problemas e intervir efetivamente, em equipe, na comunidade. A aproximação dos estudantes da vida cotidiana da comunidade propiciou o desenvolvimento de um olhar mais crítico e voltado para os problemas reais da população.

Desde 1988 participo dos projetos relacionados à monitoria. Os vários projetos, ao longo do tempo, passaram por adaptaçóes e reformas, mas sempre fizeram parte das atividades acadêmicas do Departamento de Terapia Ocupacional. A partir de 2007, o projeto de monitoria passou a ser denominado Programa de Monitoria de Graduação (PMG), cujo objetivo é incrementar as atividades de prática clínica, visando ancorar o ingresso do estudante no estágio curricular que ocorre nos três últimos períodos do curso.

Os bolsistas participam com o docente no desenvolvimento das aulas práticas e auxiliam os estudantes na articulação entre teoria e prática. Essas atividades têm contribuído para sistematizar o processo de aprendizagem, ampliar a crítica dos bolsistas em relação ao trabalho desenvolvido e aprofundar as reflexôes do grupo.

Os projetos de ensino estão presentes de maneira contínua na minha trajetória acadêmica e ao longo desses anos possibilitaram melhor compreensão do complexo processo de ensino-aprendizagem, aprimoramento das metodologias utilizadas, aproximação valiosa com o corpo discente e estabelecimento de parceria duradoura com colegas do departamento.

\subsection{A administração}

$\mathrm{Na}$ esfera administrativa, participei de órgãos colegiados internos à unidade em que estou inserida, a Escola de Educação Física, Fisioterapia e Terapia
Ocupacional (EEFFTO) e também em outras instâncias da UFMG. Essa atuação, com o tempo, expandiu-se para representaçóes externas, como no Conselho Municipal do Idoso de Belo Horizonte e na Comissão Assessora de Avaliação da Área de Terapia Ocupacional do Ministério da Educação e, ainda, para representaçóes em entidades da Terapia Ocupacional e da Gerontologia.

\subsubsection{A administração na UFMG}

Atuei na administração a partir de 1989, quando assumi o desafio de coordenar o Colegiado do Curso de Graduação em Terapia Ocupacional no biênio 1989-1991. Essa atividade resultou na apropriação do projeto pedagógico do curso e na aproximaçáo com o corpo discente. A proximidade com os estudantes possibilitou a ampliação da compreensão dos percalços administrativos no cotidiano do curso e da delicadeza necessária à transmissão do conhecimento. Nesse período em que estive na coordenação, apurei minha escuta em relação às diferentes demandas dos docentes e discentes e desenvolvi a habilidade de gerenciar negociaçóes e articular interesses diversos.

No primeiro semestre do ano 2000 fui eleita chefe do Departamento de Terapia Ocupacional e, em parceria com a Profa. Dra. Marisa Cotta Mancini, subchefe do departamento, enveredei novamente pelos caminhos da administração. $\mathrm{Na}$ chefia do departamento, nosso desafio principal foi trabalhar para atingir as metas estabelecidas pelos docentes do departamento, que incluíam a continuidade da qualificação do corpo docente, a criação de pós-graduação stricto senso (nível mestrado) e a reforma e ampliação da estrutura física do Departamento de Terapia Ocupacional e do Setor de Terapia Ocupacional no Ambulatório Bias Fortes do Complexo do Hospital das Clínicas da UFMG. Inúmeros esforços foram envidados e as metas foram atingidas com o trabalho coletivo. A parceria com a profa. Marisa foi decisiva para administrar o cotidiano do departamento e atingir as metas traçadas.

Na EEFFTO fui designada pela direção, em 2009, para coordenar o Centro de Extensão (Cenex). O Cenex congrega inúmeros programas e projetos de extensão que envolvem centenas de participantes. Esse trabalho é realizado em contato direto com a Pró-Reitoria de Extensão, onde sou representante titular na Câmara de Extensão.

Nos órgãos deliberativos da UFMG tive participação como membro titular de dois conselhos superiores: no Conselho Universitário, no período 
de 1994 a 1996, e no Conselho de Ensino Pesquisa e Extensão (Cepe). Em acréscimo, desde 2009 sou membro titular representante da área de Terapia Ocupacional na Coordenação de Residência Multiprofissional em Saúde do Hospital das Clínicas da UFMG (Coremu).

A participação em órgãos deliberativos da UFMG possibilitou a ampliação do meu cenário de atuação, maior envolvimento na vida acadêmica da universidade e o conhecimento mais aprofundado da estrutura universitária.

\subsubsection{As representações externas}

Como representante da UFMG, participei do Conselho Municipal do Idoso de Belo Horizonte por três gestôes. Como conselheira, destaco minha participação no Projeto de Capacitação de Acompanhantes de Idosos das instituiçóes conveniadas com a Prefeitura de Belo Horizonte. Participei também de uma campanha de conscientização dos motoristas dos transportes coletivos em relação ao envelhecimento da população e quanto às necessidades diferenciadas dos idosos no trânsito.

A participação como conselheira, por seis anos, possibilitou maior aproximação das reais necessidades dos idosos do município de Belo Horizonte e forneceu importantes subsídios para a reorganização dos conteúdos ministrados nas disciplinas relacionadas ao processo de envelhecimento do Curso de Graduação em Terapia Ocupacional.

Outra representação que destaco é na Comissão Assessora de Avaliação da Área de Terapia Ocupacional, vinculada à Diretoria de Estatística e Avaliação da Educação Superior (Deaes), do Instituto Nacional de Estudos e Pesquisas Educacionais Anísio Teixeira (Inep). Essa comissão tem como uma de suas atribuiçôes propor diretrizes, objetivos e outras especificaçôes necessárias à elaboração dos instrumentos de avaliação aplicados no Exame Nacional de Desempenho dos Estudantes (Enade) dos cursos de graduaçáo em Terapia Ocupacional.

Participo dessa Comissão desde 2004, ano da realização do primeiro Enade para o curso de Terapia Ocupacional. O trabalho é instigante, uma vez que enfrentamos o desafio de articular a avaliação, em nível nacional, de desempenho de estudantes com aspecto qualitativo no que se refere às competências e habilidades. Com as colegas da comissão, que trabalham em diferentes instituiçóes de ensino superior públicas e privadas do país, partilhei discussóes calorosas na busca de contribuiçóes efetivas para a construção do Sistema Nacional de Avaliação da Educação Superior (Sinaes).

Nas entidades da Terapia Ocupacional participei, nos anos 1980, da ATOMG e essa atuação criou os alicerces para outras representaçóes, como na Rede Nacional de Ensino e Pesquisa em Terapia Ocupacional (Reneto) e na Associação Brasileira dos Terapeutas Ocupacionais (Abrato).

$\mathrm{Na}$ Sociedade Brasileira de Geriatria e Gerontologia (SBGG) tive a oportunidade de conviver com inúmeros profissionais e fui eleita presidente da Gerontologia - seção Minas Gerais, por dois mandatos. A participação na SBGG resultou no convite para a elaboração de um capítulo para o Tratado de Geriatria e Gerontologia, livro que se tornou uma referência para profissionais e acadêmicos e que atualmente está em sua terceira edição.

Desde 2006 tenho atuado como revisora dos seguintes periódicos científicos: Revista Brasileira de Fisioterapia, Revista de Terapia Ocupacional da Universidade de São Paulo e Cadernos de Terapia Ocupacional da UFSCar. Integro, ainda, o Conselho Editorial da Revista de Geriatria e Gerontologia desde a sua primeira ediçáo, em 2007.

\subsection{A extensão}

Nos anos 1990 desenvolvi um primeiro projeto de extensão intitulado Comunidade de Idosos Ana Dolabella Portela Barbosa CID I (1990-1993). Esse projeto originou-se a partir de uma atividade voluntária da qual participei junto a um grupo de profissionais da área da saúde, no período de 1986 a 1990. O projeto foi desenvolvido em uma vila vicentina, em Belo Horizonte, e visava manter com independência, em um sistema comunitário, um grupo de 16 idosos, homens e mulheres. A transformação em projeto de extensão possibilitou a ampliação da participaçáo de acadêmicos e o incremento das intervençôes da Terapia Ocupacional.

$\mathrm{O}$ envolvimento e a dedicação da equipe de trabalho, acrescidos do entusiasmo dos acadêmicos voluntários e dos resultados positivos alcançados na qualidade de vida dos idosos e nos aspectos funcionais tornaram essa experiência de extensão exitosa e memorável náo apenas na esfera profissional mas também na pessoal. Esse projeto consolidou parcerias de trabalho e relaçóes de amizade. Foi um momento privilegiado na prestaçáo de assistência interdisciplinar a essa população idosa, com reuniōes clínicas bem preparadas e com discussôes instigantes. Sobretudo, foi um momento de troca de experiências e de aprender com pessoas generosas, disponíveis e brilhantes. 
Em 1993 fui convidada para participar do projeto Universidade Aberta para Terceira Idade - Projeto Maioridade, no qual, a partir de 1994, assumi a coordenação, que exerço até a presente data. Esse projeto visa fornecer informaçóes sobre os aspectos biopsicossociais que interferem no processo de envelhecimento e capacitar o idoso para um envelhecimento ativo e com qualidade. Objetiva também integrar profissionais de diversos cursos da UFMG e da comunidade num trabalho interdisciplinar.

Ao longo desses 20 anos já passaram pelo projeto centenas de idosos. Os resultados desse trabalho têm sido sistematicamente apresentados em eventos científicos regionais, nacionais e internacionais. Têm também sido tema de monografias de graduação e de dissertaçóes de mestrado.

De 1996 a 1999 participei do Lar de Idosos São José, um projeto interdepartamental que visava prestar assistência multiprofissional a idosos residentes em uma instituição de longa permanência. Os anos de atuaçáo nesse projeto foram de expressivo crescimento profissional e de trocas estimulantes de conhecimentos nas áreas de Saúde Mental e Gerontologia. Esse projeto possibilitou, ainda, a vivência das dificuldades e percalços da rotina de uma instituição para idosos e estimulou a busca de soluçôes criativas para facilitar o cotidiano dessas pessoas.

Em 1997 e 1998 participei do Programa Minas por Minas - Universidade Presente, como representante da Universidade Federal de Minas Gerais. Esse programa surgiu da preocupação das instituiçôes de ensino superior com a sociedade e visava buscar soluçóes para os problemas das regióes menos desenvolvidas. O governo do estado de Minas Gerais, a Fundação João Pinheiro e as universidades instaladas em Minas Gerais se propuseram, por meio de açóes integradas, a impulsionar o desenvolvimento dessas regiōes (FUNDAÇÃO..., 1997).

Como representante da UFMG, participei do projeto Capacitação de Acompanhantes de Idosos. Esse projeto foi financiado pelo Ministério do Trabalho por meio do Fundo de Apoio ao Trabalhador (FAT). A UFMG, em parceria com a Pontifícia Universidade Católica de Minas Gerais (PUC-Minas), ministrou cursos em Belo Horizonte e em outros municípios.

Esse projeto foi uma oportunidade impar de exercitar a interdisciplinaridade, estabelecer novas parcerias de trabalho e conhecer a realidade da prestação de cuidado ao idoso em outros municípios.

Os projetos de extensão sempre me motivaram e despertaram meu interesse e curiosidade. Acredito ser imprescindível devolver à comunidade o conhecimento produzido na universidade e considero fascinante a relação de troca de experiências e saberes que ocorre nos projetos. A atividade de extensão com a população idosa é um trabalho desafiador. Idosos com trajetórias de vida singulares vivenciam experiências novas, ampliam as interaçóes intergeracionais e partilham saberes acumulados. A realização de projetos como o Universidade Aberta para a Terceira Idade, que ocorre há muitos anos, demanda contínua avaliação, renovação de estratégias e busca de novas ferramentas metodológicas. A necessidade de inovar nos conteúdos oferecidos, a cada ano, coloca a equipe coordenadora em constante movimento de mudança, oportuniza o estudo aprofundado das temáticas e a sistematização do conhecimento.

\subsection{Atendimento ambulatorial ao idoso: do Ambulatório Bias Fortes ao Instituto Jenny Faria de Saúde do Idoso e da Mulher}

Desde 1997 coordeno o atendimento ambulatorial ao idoso realizado pela Terapia Ocupacional no Ambulatório Bias Fortes do Complexo do Hospital das Clínicas da UFMG. Esse é um trabalho integrado com os demais profissionais da área da saúde que participam do Núcleo de Geriatria e Gerontologia da UFMG (NUGG/UFMG).

$\mathrm{O}$ atendimento terapêutico ocupacional é realizado por estudantes voluntários que prestam assistência individual e/ou em pequenos grupos. Desenvolvem também um trabalho de orientação aos familiares e cuidadores dos idosos. Esse trabalho iniciou-se no Ambulatório Bias Fortes, onde o espaço físico era reduzido para o número de idosos atendidos, e atualmente é desenvolvido no Instituto Jenny Faria de Saúde do Idoso e da Mulher, inaugurado em 2010. A atuação em um espaço adequado, construído de acordo com as necessidades da população idosa, possibilitou a expansão das atividades desenvolvidas, a melhor integração da equipe e resultou na melhoria da qualidade do serviço prestado. No novo espaço, o desafio que persiste é a construção coletiva da assistência, respeitando-se as peculiaridades e integrando-se as diferenças.

\section{A capacitação}

Após oito anos de docência na UFMG, envolvida em atividades diversificadas, deparei com a necessidade de sistematizar a experiência acumulada e de aprofundar os conhecimentos sobre o envelhecimento. Era chegada a hora de ingressar em um programa de pós-graduação. Frente a esse novo desafio, participei do processo de seleção e 
ingressei no doutorado em Demografia, do Centro de Planejamento e Desenvolvimento Regional (Cedeplar) da Faculdade de Ciências Econômicas da UFMG.

\subsection{O doutorado}

Os anos do doutorado foram marcados por estudo intensivo e dedicação constante. Os conteúdos demográficos eram novos para mim, mas tive integral apoio de meus professores e de colegas, vários dos quais egressos da Faculdade de Economia.

Optei por desenvolver um projeto de pesquisa com metodologia qualitativa, pautado na escuta aos idosos. As entrevistas para a coleta dos dados foram experiências memoráveis. Entrevistei idosos que viviam em instituições e na comunidade. Os depoimentos foram pungentes, emocionados. $\mathrm{O}$ tempo da coleta de dados foi de muito trabalho e também de deslumbramento com a experiência do envelhecimento de diferentes e peculiares maneiras.

Concluí meu doutorado no início do ano 2000 e a tese foi intitulada A percepção dos idosos sobre o envelhecimento e a independência: um estudo qualitativo no município de Belo Horizonte. Foram anos de aprendizagem profissional e pessoal, nos quais encontrei pessoas muito especiais, sábias, generosas e disponíveis para compartilhar e que me deixaram marcas profundas. Com meu orientador, prof. dr. Roberto Nascimento, aprendi muito mais que Demografia, aprendi lições de desprendimento, delicadeza no trato e generosidade. Sou grata a ele por ter me orientado, compreendendo minhas limitações mas também meu interesse por trilhar um caminho tão desconhecido.

Finalizado o doutorado, meu pensamento era retornar às atividades do departamento e iniciar, juntamente com outros colegas, novas parcerias de pesquisa e de produção científica. Mas meu retorno coincidiu com a necessidade de se eleger um novo chefe de departamento. E após algumas discussóes sobre essa questấo, meu nome foi cogitado e me candidatei ao cargo. Assumir a chefia do departamento e desenvolver novas pesquisas, nesse momento, foi incompatível. Assim, adiei, temporariamente, meu projeto de enveredar pelos caminhos da pesquisa sobre o envelhecimento.

\section{Pesquisa e produção científica}

A partir de 2004, os meus primeiros projetos de pesquisa abordaram a funcionalidade do idoso, em cenários como a comunidade e as instituições de longa permanência para idosos.
Considerando que as diferentes condiçóes de saúde do idoso interferem na sua funcionalidade e geram demandas diversificadas de auxílio para o desempenho das atividades cotidianas, foi desenvolvido também um projeto de pesquisa com cuidadores de idosos atendidos no Ambulatório Bias Fortes do Complexo do Hospital das Clínicas da UFMG.

Em parceria com pesquisadores de programas de pós-graduação, os projetos foram ampliados e incluíram temas como a qualidade de vida do idoso (ABREU et al., 2007) e a tecnologia em reabilitação (ASSIS et al., 2010). A primeira pesquisa foi realizada no Programa de Pós-graduação em Ciências da Reabilitação e a pesquisa sobre tecnologia em reabilitação foi desenvolvida no Programa de Pós-graduação em Engenharia Mecânica. Essa pesquisa resultou em duas patentes registradas junto ao Instituto Nacional de Propriedade Industrial (Inpi) pela UFMG, o software Geriátrico, para estimular as funçóes cognitivas de idosos dementes, e o Dispositivo Estruturador de Rotina, que objetiva melhorar o desempenho do idoso com demência nas tarefas de vida diária. A disponibilização do software e do dispositivo váo ao encontro das necessidades dos profissionais de reabilitação e dos familiares de idosos com demência, respectivamente. A demência é uma condição de saúde que atinge número crescente de idosos no Brasil e no mundo (MACHADO, 2011) e estratégias de intervenção têm sido exaustivamente pesquisadas. Meu interesse pelo estudo da função cognitiva e pela reabilitação de idosos é antigo e foi ampliado nos anos 1990 quando, morando em Koln, Alemanha, fiz um estágio de aprimoramento na área de reabilitação cognitiva.

Outras parcerias de pesquisa nessa temática da cognição foram associadas às atividades de vida diária em diferentes níveis de demência (MARRA et al., 2007) e a estudo sobre os fatores que influenciam na gravidade da demência (MARRA et al., 2011).

Além das parcerias para pesquisa na área do envelhecimento foram também estabelecidas parcerias para estudos utilizando metodologia qualitativa, das quais resultaram estudos sobre lesão por esforço repetitivo (AUGUSTO et al., 2008), sobre funçôes e habilidades do fisioterapeuta na área esportiva (SILVA et al., 2011), sobre crenças sobre o uso do andador infantil (CHAGAS et al., 2011) e sobre terapia de restrição por movimento induzido com crianças com paralisia cerebral (MANCINI et al., 2013).

Duas outras publicações resultaram de trabalhos desenvolvidos durante o estágio curricular do curso de graduação em Terapia Ocupacional (CARDOSO; FREITAS; TIRADO, 2002; NASCIMENTO et al., 2007). Os acadêmicos foram supervisionados no desenvolvimento de estudos com grupos de idosos institucionalizados. A realização de intervenções 
grupais em instituiçóes de idosos é um desafio para os profissionais das equipes interdisciplinares, uma vez que essas instituições, no Brasil, abrigam idosos com perfis heterogêneos quanto à faixa etária, às condições de saúde e ao nível de independência/ dependência.

Em 2007, a partir de parcerias em co-orientaçáo e participação em bancas de mestrado com a profa. dra. Rosângela Corrêa Dias, iniciei a participação em um grupo multicêntrico de pesquisa denominado Fragilidade em Idosos Brasileiros - Rede Fibra. Esse estudo tem por finalidade investigar as características, a prevalência e os fatores de risco de natureza biológica, psicológica e ambiental, atuais e no curso de vida, relacionados à síndrome de fragilidade entre idosos brasileiros.

Em 2010 integrei o projeto de pesquisa intitulado Dor lombar em idosos: um estudo multicêntrico internacional entre Brasil, Austrália e Holanda - Back Complains in the Elderly: Bace. No Brasil, esse grupo é coordenado pela professora do Departamento de Fisioterapia da UFMG, dra. Leani Souza Máximo Pereira. Esse projeto objetiva estabelecer um consórcio de cooperação internacional entre pesquisadores do The George Institute for International Health, University of Sidney, o Programa de Ciências da Reabilitação dos departamentos de Terapia Ocupacional e de Fisioterapia da UFMG e o Department of General Practice at the Erasmus University Medical Center, Holanda, para estudar o perfil clínico, funcional, sociodemográfico e o curso clínico da dor lombar em idosos que procuram os serviços públicos de atenção à saúde nos países sede das instituiçôes. Trata-se de um estudo epidemiológico observacional longitudinal que acompanha 600 idosos por dois anos. Dois mestrandos que oriento desenvolvem as dissertaçóes a partir dos dados coletados nesse projeto. Um deles trabalha na tradução e adaptação cultural do instrumento Lafe Life Functional and Disability Instrument (LLFDI). A outra mestranda utilizará os dados relativos às atividades de vida diária.

Em 2011, a pesquisadora profa. dra. Maria Fernanda Lima e Costa, do Centro de Pesquisas René Rachou/Fundação Oswaldo Cruz (Fiocruz), convidou-me para integrar o grupo de pesquisadores do projeto Estudo Longitudinal das Condiçóes de Vida e de Saúde da Populaçáo Idosa Brasileira - Projeto Elsi-Brasil. O objetivo do estudo é investigar a evoluçáo e os determinantes das condiçóes de saúde, da capacidade funcional e do uso de serviços de saúde por idosos. O Elsi-Brasil cobrirá tópicos relevantes para o melhor entendimento do processo de envelhecimento e para subsidiar políticas para a promoção do envelhecimento ativo. Trata-se de um estudo de coorte de base populacional, com amostra probabilística de cerca de 15 mil pessoas com idade igual ou superior a 50 anos. Participam do projeto países da América do Norte, da Europa (consórcio de 11 países), da Ásia e o Brasil, primeiro país sul-americano a participar do consórcio. $\mathrm{O}$ grupo de pesquisadores brasileiros é constituído por profissionais de diversas áreas e as reunióes têm sido um espaço privilegiado de trocas e interaçóes. O projeto está na fase preparatória da pesquisa de campo, nela estão sendo discutidos e selecionados os protocolos para coleta de dados.

Integrar esses três grupos multicêntricos de pesquisa, com pesquisadores de grande relevância nacional e internacional, é uma oportunidade para a consolidação da minha trajetória como pesquisadora, para o alargamento dos temas pesquisados e para o estabelecimento de parcerias internacionais. Esses convites são frutos do meu investimento, de longa data, na área da Gerontologia e do trabalho comprometido na presidência da Gerontologia da Sociedade Brasileira de Geriatria e Gerontologia, seção Minas Gerais.

Como resultado de diversas parcerias de trabalho publiquei sete capítulos de livros, seis deles referentes à intervenção da Terapia Ocupacional junto a idosos (TIRADO; BARRETO; ASSIS, 2011; TIRADO; DRUMMOND, 2008; MORAES et al., 2008; TIRADO; BARRETO; LEITE, 2007; TIRADO; BARRETO, 2006; TIRADO, 2005, 2004; BARRETO; TIRADO, 2002). Outro capítulo no qual colaborei abordou a trajetória dos cursos de graduação em Terapia Ocupacional e foi elaborado em parceria com docentes dos cursos de graduação em Terapia Ocupacional que integravam a Comissão Assessora de Avaliação da Área de Terapia Ocupacional (TIRADO et al., 2006).

A elaboração de um capítulo de livro é sempre um momento de aprendizagem individual e/ou coletiva. A articulação do conhecimento com a prática clínica e a organização do texto de forma acessível e interessante são desafios a serem vencidos a cada novo capítulo elaborado. Acrescida a esses fatores, tem-se a limitada quantidade de livros nacionais de Terapia Ocupacional, o que gera demanda de investimento, dos profissionais e, especialmente, dos docentes de instituiçóes de ensino superior nesse tipo de publicação.

A temática sobre a funcionalidade do idoso tem sido a tônica das minhas investigaçóes. Em um primeiro momento foram pesquisas transversais e desenvolvidas isoladamente. No momento atual, em parceria com pesquisadores do programa de Pós-graduaçáo em Ciências da Reabilitaçáo, desenvolvo projetos mais sistematizados e estudos longitudinais. Atualmente, o estudo da função cognitiva ganhou ênfase paralelamente às 
pesquisas sobre as atividades cotidianas inicialmente desenvolvidas.

Assim vou me firmando paulatinamente no trabalho investigativo por meio da ampliação das parcerias, da sistematização e do aprofundamento das temáticas e da metodologia de pesquisa. A escolha das prioridades de pesquisa é respaldada pelo universo da clínica no cotidiano do ambulatório do Hospital das Clínicas da UFMG e das instituições de longa permanência para idosos. Os desafios são a cada dia maiores! Desenvolver pesquisas de qualidade, participar de grupos interdisciplinares, publicar em periódicos com altos índices de impacto. Frente a tantos desafios, minha estratégia é a abertura ao diálogo e às parcerias. Cooperaçáo e investimento são as palavras de ordem para circular nesse universo da produção científica. E tenho encontrado nessa travessia apoio e cooperação de pesquisadores experientes e generosos.

\section{Pós-graduação: stricto sensu e lato sensu}

A participação na pós-graduação está constituída pelo investimento em duas frentes diferentes: o stricto e o lato sensu. Descreverei essa trajetória iniciando pelo Programa de Ciências da Reabilitaçáo, posteriormente abordarei as incursóes na especialização da Terapia Ocupacional e finalizarei com a atuação na residência multiprofissional.

\subsection{O programa de Pós-graduação em Ciências da Reabilitação da UFMG}

Em 2009, respondendo a uma expectativa do departamento, fui credenciada para orientação de mestrandos no Programa de Pós-graduação em Ciências da Reabilitação. Atualmente somos três docentes orientadoras do Departamento de Terapia Ocupacional no programa. Se, por um lado, o meu ingresso atende à expectativa do departamento, amplia as possibilidades de orientação dos terapeutas ocupacionais e de produção científica, por outro esse número de orientadores é restrito para responder à crescente demanda profissional.

No Programa de Ciências da Reabilitação, desde 2003 ministro a disciplina Metodologia de Pesquisa Qualitativa e, mais recentemente, contribuo na disciplina Seminário de Dissertaçáo. Entrar na pós-graduação por meio da participação em disciplinas possibilitou maior aproximação com os colegas pesquisadores e propiciou inaugurar parcerias em co-orientaçóes, projetos de pesquisa e publicações.
Nesse programa, co-orientei três estudantes do mestrado a partir do ano de 2003. Os projetos desenvolvidos utilizaram metodologia qualitativa em sua totalidade ou em parte dos estudos. Co-orientei também mestrandas de dois outros programas, uma do Programa de Pós-graduação em Farmácia, que desenvolveu pesquisa com metodologia qualitativa, e outra do Programa de Pós-graduação em Engenharia Mecânica, que desenvolveu projeto de tecnologia para reabilitaçáo de idosos com demência. Todas essas co-orientaçóes foram o início de um caminho percorrido com cuidado, mas alto investimento, para atingir a meta do credenciamento para orientaçáo.

O credenciamento no Programa de Ciências em Reabilitação, em 2009, foi concretizado com o apoio de colegas pesquisadores que me incluíram na atividade de co-orientação, nas bancas de defesa de dissertaçóes e teses e nas parcerias para publicaçôes. Entrar no universo da pesquisa e, consequentemente, da publicação é tarefa árdua que envolve grande esforço e dedicação na qual um pesquisador isolado dificilmente encontra êxito. Agradeço a parceria com as professoras do Departamento de Fisioterapia, dra. Leani Souza Máximo Pereira e dra. Rosângela Corrêa Dias. Agradecimento muito especial registro aqui à colega e amiga professora do Departamento de Terapia Ocupacional dra. Marisa Cotta Mancini, profissional brilhante, de ampla projeção no cenário nacional e internacional do ensino e da pesquisa, que de maneira generosa e disponível me conduziu pela mão nessa entrada no programa de pós-graduação.

Iniciei a orientação em 2010 e a participação na pós-graduaçáo stricto sensu é um projeto em curso que gradualmente ganha amplitude.

\subsection{A especialização em Terapia Ocupacional}

Em 2003 fui designada para integrar a Comissão de Implantação do Curso de Especialização em Terapia Ocupacional. Juntamente com outras colegas, após período de produtivas discussões, elaboramos uma proposta que foi aprovada e em 2004 iniciamos a oferta do curso lato sensu Especializaçáo em Terapia Ocupacional.

No biênio 2004-2005 coordenei a área de gerontologia e retornei a essa funçáo no período de 2008-2009. Na especializaçáo participei desde o primeiro ano do processo de seleçáo dos candidatos, ministrei disciplinas e orientei trabalhos de conclusão de curso (TCC).

Até 2010 passaram pela especialização da Terapia Ocupacional centenas de profissionais que retornaram à universidade em busca de atualização de conhecimentos e de novos saberes. Sabemos que 
na trajetória profissional inovar algumas vezes é difícil. Mas é sempre necessário descobrir novos caminhos para lidar com a cognição, o humor, as emoçôes e as diferentes alteraçóes apresentadas pelos idosos. Essa busca por novos caminhos demanda esforço pessoal, disciplina, dedicação, paciência e grande dose de sensibilidade e delicadeza, que foi compartilhada na trajetória da especialização durante sete anos.

\subsection{A residência integrada multiprofissional em saúde}

A residência é uma modalidade de ensino de pós-graduação lato sensu destinada às profissóes que se relacionam à saúde e tem como objetivo capacitar os profissionais para o trabalho em equipe, humanizar a assistência e promover a integralidade da atenção. No Hospital das Clínicas da Universidade Federal de Minas Gerais são oferecidas duas áreas de concentração, Atenção à Saúde do Idoso e Atenção Cardiovascular.

$\mathrm{Na}$ residência participo desde a fase de elaboração do projeto, em 2009, e atualmente atuo como tutora da área de Terapia Ocupacional, na atenção à saúde do idoso. Numa análise preliminar desse percurso, ressalto como pontos positivos o aprimoramento das relaçóes interdisciplinares de trabalho e o estabelecimento de parcerias para ministrar as disciplinas.

O cotidiano de trabalho na residência multiprofissional nos coloca continuamente frente a novas demandas e à necessidade de flexibilidade e abertura para incorporar ao saber acadêmico os diferentes saberes dos cenários de prática, um trabalho que exige ajustes frequentes e ampla disponibilidade para o debate e busca por soluçóes criativas para os problemas. Atuar como tutora da residência colocou-me em movimento contínuo e alterou muitas vezes a rota de trabalho que eu preestabelecera.

Os programas de pós-graduação, stricto sensu e lato sensu, apresentam como similaridades a necessidade de busca constante da reciclagem e da própria renovação como docente e pesquisador. Os desafios crescem, diariamente, em tamanho e complexidade na orientação de mestrandos e na tutoria de residentes. Estar aberto a mudanças, atento à produçáo incessante de novos conhecimentos e disponível para aprender é fundamental. As paradas para reflexão e revisão de percurso são aliadas imprescindíveis nessa travessia, assim como a parceria e o apoio constante de outros pesquisadores mais experientes. Consciente das inúmeras possibilidades, mas, sobretudo, entusiasmada com elas, sigo o caminho!

\section{Perspectivas da trajetória}

Ao refazer o caminho percorrido na minha trajetória profissional, muitos sentimentos se misturam. Sentimento de alegria, pelas conquistas alcançadas e desafios enfrentados nesses 27 anos de docência; de gratidão, pelas parcerias estabelecidas e conhecimentos agregados; mas também de inquietação, em relação às novas rotas que devem ser traçadas.

Nesse ponto do percurso, muitas possibilidades se apresentam. A produção do conhecimento me desafia, o processo de formação me fascina, a incursão pela administração me instiga. A vontade de seguir aprendendo me motiva e indica a necessidade de investimento no pós-doutorado, visando aprofundamento teórico e busca por conhecimentos inovadores. Outra perspectiva que vislumbro é de maior envolvimento com a produção e publicação de artigos em periódicos científicos. O investimento na publicação tem crescido gradativamente e tem sido um dos grandes desafios atrelados à orientaçáo dos mestrandos.

No processo de formação de terapeutas ocupacionais, as perspectivas sinalizam o incremento da educação continuada. Na graduação pretendo continuar contribuindo na Comissão de Implantaçâo do Currículo, atenta aos movimentos de mudança do corpo docente e discente, investida em projetos de ensino que possibilitem o olhar transformador em relação à aprendizagem em saúde e em projetos de extensão que promovam a integração e valorização da população idosa.

Minha trajetória como professora, orientadora e pesquisadora é marcada pelo envolvimento e pela obstinação na busca de conhecimento e aprimoramento. Percorro uma trajetória dinâmica que engloba diversificadas frentes de atuação, na qual procuro desenvolver parcerias profissionais e estreitar laços de amizade para tornar essa travessia mais leve e compartilhada.

Ao mergulhar na minha história e resgatar eventos marcantes de minha trajetória, avalio a importância de ter enfrentado os desafios com coragem e ousadia; de estar, constantemente, permeável ao novo; e de manter abertos os espaços de escuta. Sigo aprendendo, pesquisando, produzindo, publicando, ensinando!

\section{Referências}

ABREU, N. S. et al. Qualidade de Vida na Perspectiva de Idosas com Incontinência Urinária. Revista Brasileira de Fisioterapia, São Carlos, v. 11, n. 6, p. 429-436, 2007. http://dx.doi.org/10.1590/S1413-35552007000600003 
ASSIS, L. O. et al. Evaluation of cognitive tecnologies in geriatric rehabilitation: a case study pilot project. Occupational Therapy International, London, v. 17, p. 53-63, 2010. http://dx.doi.org/10.1002/oti.290

AUGUSTO, V. G. et al. Um Olhar sobre a LER/DORT no contexto clínico do fisioterapeuta. Revista Brasileira de Fisioterapia, São Carlos, v. 12, n. 1, p. 49-56, 2008. http://dx.doi.org/10.1590/S1413-35552008000100010

BARRETO, K. M. L.; TIRADO, M. G. A. Terapia ocupacional em gerontologia. In: FREITAS, E. V. et al. Tratado de Geriatria e Gerontologia. Rio de Janeiro: Guanabara Koogan, 2002. p. 866-871.

BRAGA, L. Z. L. et al. Acesso e utilização da informação no ensino de Terapia Ocupacional na UFMG. In: CONGRESSO BRASILEIRO DE TERAPIA OCUPACIONAL, 10., 2007, Goiânia. Anais... Goiânia: Associação dos Terapeutas Ocupacionais de Goiás, 2007. Apresentação oral.

CAMPOS, G. W. S. Saúde paideia. São Paulo: Hucitec, 2003. p. 85-102.

CARDOSO, A. P.; FREITAS, L. C.; TIRADO, M. G. A.; Oficina de som e movimento: um espaço de intervenção terapêutico ocupacional. Revista de Terapia Ocupacional da USP, Sáo Paulo, v. 13, p. 51-55, 2002.

CHAGAS, P. S. C. et al. Crenças sobre o uso do andador infantil. Revista Brasileira de Fisioterapia, São Carlos, v. 15, n. 4, p. 303-9, 2011. http://dx.doi.org/10.1590/ S1413-35552011005000015

FUNDAÇÃO JOÃO PINHEIRO. Programa Minas por Minas. Belo Horizonte: Universidade Presente, 1997. 62 p. Relatório.

MACHADO, J. C. B. Doença de Alzheimer. In: FREITAS, E. V. et al. Tratado de Geriatria e Gerontologia. Rio de Janeiro: Guanabara Koogan, 2011. p. 178-201.

MANCINI, M. C. et al. How do children and caregivers perceive their experience of undergoing CIMT protocol and its effects? Scandinavian Journal of Occupational Therapy, Oslo, 2013 May 29. [Epub ahead of print].

MARRA,T. A. et al. Influence of socio-demographic, clinical and functional factors on the severity of dementia. Archives of Gerontology and Geriatrics, Amsterdam, v. 53, p. 210-215, 2011. http://dx.doi.org/10.1016/j. archger.2010.11.001

MARRA, T. A. et al. Avaliação das atividades de vida diária de idosos com diferentes níveis de demência. Revista Brasileira de Fisioterapia, São Carlos, v. 11, p. 267-273, 2007. http://dx.doi.org/10.1590/ S1413-35552007000400005

MORAES, E. N. et al. Tratamento dos sintomas comportamentais e reabilitaçáo cognitiva. In: MORAES,
E. N. Principios básicos de geriatria e gerontologia. Belo Horizonte: Coopmed, 2008. p. 359-370.

NASCIMENTO, V. P. et al. Grupo de leitura e produção de textos: uma intervenção da terapia ocupacional. Revista de Terapia Ocupacional da USP, São Paulo, v. 18, p. 17-21, 2007.

SILVA, A. A. et al. Análise do perfil, funçôes e habilidades do fisioterapeuta com atuação na área esportiva nas modalidades de futebol e voleibol no Brasil. Revista Brasileira de Fisioterapia, São Carlos, v. 15, n. 3, p. 219-26, 2011. http://dx.doi.org/10.1590/ S1413-35552011000300008

TIRADO, M. G. A. Reabilitação e manutenção da capacidade funcional. In: SALDANHA, A. L.; CALDAS, C. P. Saúde do idoso: a arte de cuidar. Rio de Janeiro: Interciência, 2004. p. 144-151.

TIRADO, M. G. A. Intervenção terapêutica ocupacional junto ao idoso com distúrbios cognitivos. In: TAVARES, A. Compêndio de neuropsiquiatria geriátrica. Rio de Janeiro: Guanabara Koogan, 2005. p. 571-578.

TIRADO, M. G. A. Apoio à implantação do projeto pedagógico do curso de Terapia Ocupacional/ UFMG. In: SEMANA DA GRADUAÇÃO DA UFMG, 10., 2006, Belo Horizonte. Anais... Belo Horizonte: UFMG, 2006. Pôster.

TIRADO, M. G. A.; BARRETO, K. M. L. Terapia ocupacional em gerontologia. In: FREITAS, E. V. et al. Tratado de geriatria e gerontologia. Rio de Janeiro: Guanabara Koogan, 2006. p. 1210-1215.

TIRADO, M. G. A.; BARRETO, K. M. L.; ASSIS, L. O. Terapia Ocupacional em Gerontologia. In: FREITAS, E.V. et al. Tratado de Geriatria e Gerontologia. Rio de Janeiro: Guanabara Koogan, 2011. p. 1422-1428.

TIRADO, M. G. A.; BARRETO, K. M. L.; LEITE, V. M. M. Terapia ocupacional, dor e cuidados paliativos no processo de envelhecimento. In: DE CARLO, M. M. R. P.; QUEIROZ, M. E. G. Dor e cuidados paliativos: terapia ocupacional e interdisciplinaridade. São Paulo: Roca, 2007. p. 288-306.

TIRADO, M. G. A.; DRUMMOND, A. F. Intervenção do terapeuta ocupacional em instituiçóes de longa permanência para idosos. In: DRUMMOND, A. F.; REZENDE, M. B. Intervençóes da Terapia Ocupacional. Belo Horizonte: UFMG, 2008. p.159-175.

TIRADO, M. G. A. et al. Terapia ocupacional. In: HADDAD, A. E. et al. A trajetória dos cursos de graduação na saúde 1991-2004. Brasília: Instituto Nacional de Estudos e Pesquisas Educacionais Anísio Teixeira, 2006. p. 489-528.

WILLARD, H. S.; SPACKMAN, C. S. Willard \& Spackman terapéutica ocupacional. Barcelona: Jims, 1973. 